\title{
Recommendations for the use of opioids in Brazil: Part III. Use in special situations (postoperative pain, musculoskeletal pain, neuropathic pain, gestation and lactation)*
}

\author{
Recomendações para uso de opioides no Brasil: Parte III. Uso em situações especiais (dor pós- \\ operatória, dor musculoesquelética, dor neuropática, gestação e lactação)
}

Durval Campos Kraychete ${ }^{1}$, José Tadeu Tesseroli de Siqueira ${ }^{2}$, Telma Regina Mariotto Zakka ${ }^{3}$, João Batista Santos Garcia ${ }^{4}$ and Specialists Group

${ }^{*}$ Received from the Brazilian Society for the Study of Pain, São Paulo, SP, Brazil.

DOI 10.5935/1806-0013.20140030

\section{ABSTRACT}

BACKGROUND AND OBJECTIVES: The use of opioids as first and second line agents to adequately treat pain requires systematization in different clinical syndromes which course with acute pain. This study aimed at discussing recommendations for the use of opioids in acute postoperative pain, neuropathic pain, musculoskeletal pain and pain during gestation and lactation.

CONTENTS: This review has addressed the use of opioids in frequent chronic and acute painful syndromes, in gestation and lactation, discussing indications, drugs used, doses, risks, complications and recommendations.

CONCLUSION: Opioids for acute postoperative pain have been broadly studied and are established for minor medium and major surgeries. Recommendations for the use of opioids in neuropathic and musculoskeletal pain are restricted to second line treatment and require further discussions. Few studies have investigated the interaction of opioids with physiologic changes typical of gestation and the repercussions of the use of such agents to treat acute and chronic pain in the short and long term.

Keywords: Gestation, Lactation, Musculoskeletal pain, Neuropathic pain, Opioid, Postoperative pain.

\footnotetext{
1. Federal University of Bahia, Salvador, BA, Brazil.

2. University of São Paulo, São Paulo, SP, Brazil.

3. University of São Paulo, School of Medicine, Clinicas Hospital, Interdisciplinary Pain Center, São Paulo, SP, Brazil.

4. Federal University of Maranhăo, Săo Luis, MA, Brazil.

Correspondence to:

Durval Campos Kraychete

Rua Rio de São Pedro, 327/401 - Bairro Graça

40150-350 Salvador, BA, Brasil.

E-mail: dkt@terra.com.br
}

(C) Sociedade Brasileira para o Estudo da Dor

\section{RESUMO}

JUSTIFICATIVA E OBJETIVOS: O emprego de opioides como agentes de primeira e segunda linha no tratamento da dor ainda é motivo de discussão na literatura. $\mathrm{O}$ uso de opioides de maneira adequada exige sistematização em diversas síndromes clínicas que cursam com dor aguda e crônica. O objetivo deste estudo foi discutir recomendações para o emprego de opioides na dor aguda de pós-operatório, na dor neuropática, na dor musculoesquelética e na dor durante a gestação e lactação.

CONTEÚDO: Nesta revisão abordou-se o emprego de opioides em síndromes dolorosas agudas e crônicas frequentes, na gestação e lactação discutindo as indicações, os fármacos utilizados, as doses, os riscos, as complicaçôes e as recomendaçóes. CONCLUSÁO: O uso de opioides na dor aguda pós-operatória tem sido bem estudado e está estabelecido em cirurgias de pequeno, médio e grande porte. As recomendaçóes para o emprego de opioides na dor neuropática e musculoesquelética são restritas à segunda linha de tratamento e exigem futuras discussôes. Poucos estudos investigaram a interaçấo dos opioides com as alteraçôes fisiológicas próprias da gestação e as repercussôes do emprego desses agentes no tratamento da dor aguda e crônica em curto e em longo prazo.

Descritores: Dor musculoesquelética, Dor neuropática, Dor pós-operatória, Gestação, Lactação, Opioide.

\section{INTRODUCTION}

The correct and monitored use of opioids is still a challenge for health professionals. So, by initiative of a group of specialists, with institutional validation of the Brazilian Society for the Study of Pain (SBED), we decided for a publication, the major proposal of which is to present recommendations to guide health professionals in the use of opioids to control acute and chronic pain. Continuing with our work, this study will discuss the use of opioids in acute postoperative pain, neuropathic pain, musculoskeletal pain, pain in pregnant women and during lactation. Recommendations presented here and in future publications in a sequenced manner, aim at starting the development of a practical guide for the adequate treatment of patients, disclosing available recommendations with regard 
to the use of opioids in different clinical situations, encouraging studies related to their safety and effectiveness, as well as at demystifying the inadequate association between addiction/ dependence and the use of opioids.

\section{OPIOIDS FOR POSTOPERATIVE PAIN}

Opioids may be prescribed to treat acute postoperative pain after minor, medium or major surgeries or after outpatient procedures. So, when using opioids by any route, pain evaluation and measurement should be constant, by monitoring, recording and treating adverse effects, as well as by adjusting doses according to pain intensity and patients' sedation level ${ }^{1}$.

Opioids administration routes may be oral, intravenous, intra-articular, epidural, subarachnoid and subcutaneous ${ }^{1}$. Most common adverse effects observed in the postoperative period are itching, nausea, vomiting, urinary retention, sleepiness, dizziness and constipation ${ }^{2}$. Most feared adverse effect is respiratory depression, the incidence of which is approximately $0.25 \%^{3}$.

Continuous or intermittent intravenous administration of tramadol hydrochloride, morphine and fentanyl is indicated for moderate to severe pain or when the oral route cannot be used. These drugs should be used with caution and initial dose should be low in the elderly, in the presence of liver and renal disease, prostate hypertrophy and intracranial hypertension ${ }^{4}$. Intravenous patient-controlled analgesia (PCA) is effective alternative to control postoperative pain, allowing that minimum necessary opioid analgesic dose be progressively titrated and adjusted according to age, pain evaluation and patients' clinical status. This prevents undesirable adverse effects, decreasing of drug blood concentration and the gap generally existing between analgesic request and its preparation and administration by the nursing team ${ }^{5}$. Epidural PCA for abdominal surgical procedure induces better pain control as compared to intravenous PCA, however patients refer more itching ${ }^{6}$. Patients duly oriented by the pain group will feel safe and independent, resulting in a better quality of analgesia as compared to conventional methods.

\section{Drugs}

Tramadol: may be administered to relief mild to moderate pain and may produce adverse effects such as irritability, headache, nausea, vomiting, diaphoresis and dizziness ${ }^{7}$.

Oxycodone: with controlled release, it is safe and effective to control postoperative pain as compared to intravenous morphine for orthopedic surgeries ${ }^{8}$.

Caution: prolonged action opioids should be used with caution.

Fentanyl: it is also used for epidural analgesia in continuous infusion or fractioned doses. It has fast onset of action and short duration of effects. Transdermal route is not indicated for patients needing fast titration, as the case of postoperative pain?.

Morphine: it has been prescribed as golden-standard for postoperative analgesia of medium and major surgical procedures, by intravenous, epidural and subarachnoid routes ${ }^{4}$. The association of intra-articular morphine $(4 \mathrm{mg})$, ropivacaine $(90 \mathrm{mg})$ and ketorolac $(30 \mathrm{mg}$ ) for shoulder surgeries decreases systemic morphine consumption ${ }^{10}$. Intra-articular morphine in the knee in the postoperative period with doses above $5 \mathrm{mg}$ is also effective $^{11}$. It is important to point out that subcutaneous route, in addition to being as effective as the intravenous route, has bioavailability equivalent to the oral rout, is better accepted by patients and operational cost is low ${ }^{12}$. Continuous infusion morphine to reach plasma balance for analgesia may take 4 to 6 half-lives ${ }^{13}$, so, one should remind that the PCA concept takes into account that: 1 ) there is variation among individuals in the need for opioids, which may be of 4 times or more; 2) minimum effective analgesic concentration is not constant; 3) any dose may be excessive for some and not enough for others; 4) transition from severe pain to effective analgesia involves minor serum concentration changes ${ }^{12,13}$.

Codeine: it is available as combined presentation with paracetamol, diclofenac or alone. In single $60 \mathrm{mg}$ doses for minor to medium surgeries it seems to promote analgesia in few individuals with relief of approximately $26 \%{ }^{14}$.

Peripheral anesthetic blocks: there are no evidences supporting the use of the association of opioids for peripheral anesthetic blocks ${ }^{15}$.

\section{Spinal administration}

The infusion of local anesthetic solutions with opioids combines faster analgesia of local anesthetics and more prolonged opioids analgesia ${ }^{3}$. Epidural and subarachnoid routes provide more prolonged analgesia with lower concentrations as compared to the systemic route. Low doses decrease the incidence of respiratory depression ${ }^{4}$.

The association of spinal opioids and adjuvants may result in adequate analgesic control ${ }^{16}$. Subarachnoid sufentanil produces analgesic concentration with doses of 12.5 and $25 \mu \mathrm{g}$, but may induce early respiratory depression within 30 minutes $^{17}$.

Caution: sufentanil dose should vary from 2 to $10 \mu \mathrm{g}$ to produce analgesia within 1-20 minutes after labor analgesia, but increases the incidence of itching ${ }^{18}$.

Opioids administration in single or intermittent doses via catheters has incidence of respiratory depression between 0.01 and $3 \%$. When compared to parenteral administration (intravenous or venous PCA), there is no difference in the frequency of respiratory depression and is associated to less sleepiness and sedation ${ }^{19}$.

\section{OPIOIDS FOR MUSCULOSKELETAL PAIN}

\section{Osteoarthritis}

Symptomatic osteoarthritis progresses in a pattern which includes joint pain, strength loss, gait incapacity and physical fitness decrease. Studies with opioids for chronic knee and hip osteoarthritis pain are still controversial. Some authors analyzing six clinical trials (tramadol, codeine, morphine and oxycodone) for knee osteoarthritis have observed that the analgesic effect was better between the second and fourth weeks, with clinically 
non significant pain decrease. There has been loss of patients' follow-up due to adverse effects ${ }^{20}$.

Extended release tramadol in the dose of 200 to $300 \mathrm{mg}$ was more effective than placebo when pain, stiffness and function were evaluated with the WOMAC tool (Western Ontario and McMaster Universities). There have been more adverse effects (constipation, dizziness, nausea, sleepiness and headache) with the dose of $400 \mathrm{mg} / \mathrm{day}^{21}$. A meta-analysis with 11 clinical trials has observed that one out of six individuals using tramadol or the association tramadol and paracetamol have improved pain, joint stiffness and daily life activities. Adverse effects were well tolerated $^{22}$.

Opioids (codeine, oxycodone, morphine) were also effective to improve pain, stiffness and function by the WOMAC tool, and sleep quality, as compared to placebo in clinical trials and a systematic review with meta-analysis ${ }^{23-25}$. Codeine dose has varied from 100 to $300 \mathrm{mg}$, oxycodone dose from 20 to $40 \mathrm{mg} /$ day and morphine dose from 30 to $50 \mathrm{mg} /$ day. Extended release opioids were used. Pain decrease was approximately 20 to 30\% and was maintained to up to 60 days; adverse effects were tolerable (nausea, vomiting, itching and headache).

\section{Chronic low back pain}

Opioids may be considered to treat chronic low back pain more than to improve functional capacity. They are more effective than placebo and comparable to anti-inflammatory drugs. Adverse effects limit its prolonged use ${ }^{26}$. However a recent meta-analysis with 5540 patients has observed that opioids (morphine, oxycodone, tapentadol) were better than placebo to relief pain and improve functional capacity. Tramadol has also promoted further pain relief and improvement of daily life activities as compared to placebo for low back pain ${ }^{27}$.

There have been no reports of severe adverse effects, risks of addiction or overdose and severe complications (apnea, hyperalgesia or hypogonadism). Clinical trials were of low to moderate quality, there have been many follow-up losses, short observation period and limited interpretation of functional improvement. Authors have concluded that effectiveness and safety of prolonged use of opioids for chronic low back pain are still lacking evidences.

\section{Fibromyalgia}

Tramadol and tramadol/paracetamol relieve fibromyalgia pain. The effect was better as compared to placebo and has improved several FIQ (Fibromyalgia Impact Questionnaire) aspects ${ }^{28}$. Mean tramadol dose has varied from 150 to $200 \mathrm{mg}$ and adverse effects were tolerable. However, opioids are not recommended for patients with this syndrome since risks do not outweigh benefits ${ }^{29}$.

\section{OPIOIDS FOR NEUROPATHIC PAIN}

In the past, opioids were considered ineffective for neuropathic pain and many patients were inadequately treated for not using such agents. Opioids may be used during the titration of first line drugs and for acute neuropathic pain in patients already treated or who will start treatment. Recent guidelines, however, include opioids as second line drugs to treat neuropathic pain in patients not responding to first line drugs. This because: 1 ) there are no studies on the safety of prolonged use; 2) they cause more adverse effects than tricyclic drugs and gabapentinoids; 3) may induce hyperalgesia.

Due to different neuropathic pain (NP) etiologies it is not possible to determine in which patient or disease the opioid will be more effective and for how long, since in most studies observation periods were not long. Pain relief, however, was considered satisfactory ${ }^{30-36}$. Such data may be evidenced by NNT (necessary number to treat) which is the number of patients who shall be treated with a given drug to obtain $50 \%$ pain intensity decrease. NNT shall be used only in placebo-controlled studies. The lower the NNT, the better the drug efficacy (Table 1) ) $^{31,36}$. Recommended doses are also described (Table 2).

Table 1. Necessary number to treat (NTT) of opioids (per available study)

\begin{tabular}{lc}
\hline Drug or class & NNT (study) \\
\hline Tramadol & $3.4^{30}$ \\
& $3.9^{36}$ \\
& $9.0^{36}$ \\
Opioids & $2.6^{30}$ \\
Morphine & $2.5^{36}$ \\
Oxycodone & $2.6^{36}$ \\
\hline
\end{tabular}

Table 2. Tramadol and opioid doses to treat neuropathic pain

\begin{tabular}{lll}
\hline Drugs & Dose & Observations \\
\hline Codeine & $\begin{array}{l}20-180 \mathrm{mg} / \text { day } \\
\text { Tramadol }\end{array}$ & $\begin{array}{l}\text { Treatment with tramadol may } \\
\text { be started with } 50 \mathrm{mg} \text { once or } \\
\text { twice a day and then gradually } \\
\text { increased in } 50-100 \mathrm{mg} / \text { day, as } \\
\text { necessary, until } 400 \mathrm{mg} / \text { day. } \\
\text { Dose varies among patients or } \\
\text { as needed }\end{array}$ \\
$\begin{array}{lll}\text { Morphine LC } \\
\text { Oxycodone } \\
\text { Methadone }\end{array}$ & $\begin{array}{l}10-300 \mathrm{mg} / \mathrm{d} \\
10-120 \mathrm{mg} / \mathrm{day}\end{array}$ & $\begin{array}{l}\text { There are no clinical trials on this } \\
\text { drug }\end{array}$ \\
\hline
\end{tabular}

\section{OPIOIDS AND GESTATION}

Studies on drug risk estimates during gestation and lactation were case reports, epidemiological, cohort and retrospective studies and studies with experimental animals. Such studies present variables, such as mother's clinical-nutritional status, maternal age, use of alcohol and illicit drugs, smoking, gestational age, drug dose, genetic history and environmental toxins which interfere with authors results and conclusions.

To guide drug prescription during gestation and lactation, the Food and Drug Administration $(\mathrm{FDA})^{37}$, in the United States of America, has developed a risk classification based on medication potential to cause fetal malformations. Yankowitz and Nieby ${ }^{38}$ have reviewed and rewrote in a more practical way the four classification categories proposed by the FDA (Table 3). 
Table 3. Risk classification of drugs during gestation

\begin{tabular}{ll}
\hline A & Controlled studies have not shown risk \\
B & There is no evidence of risk for humans \\
C & Risk cannot be ruled out; recently introduced and/or still not \\
& studied drugs are included \\
D & There is positive evidence of risk \\
X & Not indicated during pregnancy \\
\hline
\end{tabular}

This classification is an orientation for the prescription moment, which shall consider gestational period for therapeutic safety. Criteria for selecting and prescribing drugs should be based on the cost-benefit ratio of each clinical situation.

Much of what is known about the effects of chronic exposure to opioids during pregnancy is based on drug addiction studies, being heroin and methadone the most widely used by pregnant women for pain relief or abuse ${ }^{39}$.

Most studies suggest the association of methadone and neonates with low weight and smaller cephalic perimeter, but increase of congenital malformations has not been observed. FDA places methadone in Category B, provided it is not used in high doses and/or close to term ${ }^{40}$.

Neonatal withdrawal syndrome is present in 30 to $90 \%$ of newborns (NB) exposed to heroin or methadone during gestation and symptoms are more frequent with daily methadone doses above $20 \mathrm{mg}$. Neonatal withdrawal syndrome symptoms include unrest, irritability, difficulty to breastfeed, weight loss and, in severe cases, seizures.

NB with opioids withdrawal syndrome in general are symptomatic during 48 postpartum hours, however symptoms may appear or persist for 7 to 14 days. Methadone levels in maternal milk seem to be enough to prevent infants' withdrawal symptoms ${ }^{41,42}$. The American Academy of Pediatrics (AAP) considers that neonatal withdrawal syndrome is mild with methadone and is compatible with lactation in the dose of up to $20 \mathrm{mg} /$ day ${ }^{43}$.

Opioids directly reach the fetus via placental transfer or indirectly by uterine tone alteration. Low molecular and liposoluble opioids cross the placenta more easily and the amount of free drug depends on placental blood flow and on the level of binding to maternal proteins ${ }^{44,45}$.

In postoperative analgesia of pregnant women submitted to non-obstetric surgeries, fentanyl, morphine and hydromorphone are safe and effective alternatives for parenteral administration. Drugs administered for postoperative analgesia in spinal compartments minimize maternal plasma concentration of opioids and decrease placental transfer to the fetus or infant exposure $^{46}$.

To date, there are no data showing the presence of sequelae after prolonged intrauterine exposure to opioids, especially major or minor malformations (Table 4). Study carried out at the Michigan Medical has shown lack of teratogenic effects in 289 fetuses exposed to oxycodone. The Collaborative Perinatal Project has monitored 50282 pregnant women who have used opioids during gestation and there have been reports of respiratory malformations associated to the use of codeine $e^{39,47}$. So, codeine is considered Category C.
Table 4. Risk classification of drugs during gestation

\begin{tabular}{ll}
\hline Risk & Opioids \\
\hline A & - \\
B & Morphine, methadone, fentanyl, meperidine, hydromor- \\
& phone, oxycodone \\
C & Codeine, tramadol \\
D & - \\
X & - \\
\hline
\end{tabular}

Hydromorphone: not available in Brazil.

\section{Drugs $^{47-52}$}

Codeine: used during gestation may be associated to fetal malformations in the first and second trimesters, to low analgesic efficacy and constipation. Constipation is especially undesirable during gestation since women have already this symptom and hemorrhoids.

Tramadol: it use during pregnancy and lactation is limited, since there are no sufficient clinical investigation with this population. Tramadol has lipophilic characteristics, freely crosses the placenta and may determine NB withdrawal syndrome.

Fentanyl: parenteral fentanyl in the preoperative period may induce NB respiratory depression when administered immediately before birth. Maternal administration of fentanyl or other opioid may determine alteration in fetal heart rate variability and fetal hypoxemia. Maternal-fetal exchange of fentanyl is fast, with increased umbilical venous blood concentration 5 minutes after intravenous administration in pregnant women. In term gestation, epidural fentanyl and alfentanil establish a fast balance between mother and fetus and are found in placental intervillous spaces after birth.

Meperidine: repeated doses may lead to build-up of its metabolites (normeperidine) and may produce central nervous system excitation with generalized shivering, myoclonus and seizures. Significant normeperidine build-up is unlikely in parturients receiving single dose, however, meperidine is not better than other parenteral opioids and should be avoided.

Morphine: during gestation there is morphine pharmacokinetic alteration, plasma clearance is increased, half-life is decreased, distribution volume decreases and 3-glucoronide metabolite formation is increased. Morphine and its metabolite rapidly cross the placenta and establish maternal-fetal balance in approximately 5 minutes, so that concentrations in umbilical cord blood are similar to those observed in maternal blood. Methadone: transfer and clearance indices are significantly higher on fetal-maternal direction than on mother-fetus direction, without adverse effects on placental viability and on functional parameters, in spite of the retention of a large percentage in placental tissue. Methadone does not have active metabolites and, differently from morphine, may be used for long periods. During gestation there is increased methadone metabolism and some pregnant women, who used the same dose in the long term, present withdrawal syndrome in the third trimester. Dose fractioning, without increasing total dose, may decrease withdrawal symptoms.

In the postpartum, probably due to the lack of placental metabolism, the same methadone dose results in higher levels 
as compared to the third trimester. Women who have chronically used opioid analgesia in general decrease the dose to the level before gestation. Many women have cut the dose in half one day after delivery or have increased the interval between doses.

According to the Canadian Guideline for Safe and Effective Use of Opioids for Chronic Non-Cancer Pain ${ }^{50}$, pregnant women with chronic non-cancer pain or being treated with opioids for a long time should gradually decrease the dose and, if possible, discontinue its use during gestation. Opioid withdrawal should be slow to prevent irritating uterine smooth muscles and consequently miscarriage or premature labor. In chronic non-cancer pain pregnant women depending on opioid prescription, treatment with methadone is recommended.

\section{OPIOIDS AND LACTATION}

Drugs to be used during lactation are classified as safe, moderately safe, indicated with caution and contraindicated.

Safe drugs are those not producing adverse effects on infant and maternal milk. Agents used with caution during lactation are those with evidences of risk to infant health or milk production. Their use for shorter time and in the minimum possible dose is recommended, strictly observing the infant. Drugs contraindicated during lactation are those where evidences have shown that cause significant damages to infant health and require interruption of lactation ${ }^{43,53,54}$.

Opioid analgesics are excreted in maternal milk and are classified as:

1. Safe during lactation: fentanyl and propoxyphene;

2. Moderately safe: codeine, tramadol, morphine, hydromorphone, methadone and oxycodone.

The American Academy of Pediatrics (AAP) considers compatible with lactation the use of opioids such as codeine, fentanyl, methadone, morphine and propoxyphene ${ }^{43}$.

Pharmacokinetic analysis has shown that codeine and morphine concentrations in maternal milk are equal or slightly higher that concentrations in maternal plasma. Morphine is transferred to maternal milk in small amounts and neonatal exposure is limited due to its poor bioavailability ${ }^{33,54}$.

After absorption by NB gastrointestinal tract, opioids are metabolized. Morphine is glucorinated in inactive metabolites. Meperidine suffers $\mathrm{N}$-demethylation in normeperidine, active metabolite with significantly long half-life in the NB. Regular lactation leads to the build-up of normeperidine resulting in neurobehavioral depression and seizures ${ }^{53,54}$.

There are no evidences of adverse behavioral effects in children exposed to tramadol, so its use in the postpartum is considered compatible with lactation. Oxycodone is present in maternal milk up to 72 hours after its administration, however in low concentration which poses no risk to the infant $t^{53,54}$.

Oral methadone transfer to the maternal milk is minimal, occurs regardless of the dose used by the mother and adverse effects on infants are distinct ${ }^{53,54}$.

NBs with prenatal exposure to opioids for long periods require weaning to be very slow (decrease of $10 \%$ every three days) to prevent withdrawal symptoms. Methadone levels in maternal milk seem to be enough to prevent infant withdrawal symptoms $s^{53,54}$.

According to AAP, prenatal or neonatal exposure to opioids may induce acute toxicity, finding that suggests drug effect in the long term or its slow weaning to prevent neonate withdrawal symptoms. In neonates at risk, hospital discharge should be delayed until the absence of withdrawal signs and symptoms for the period of 24 to 48 hours and after opioids are completely discontinued ${ }^{43,53,54}$.

Support assistance for withdrawal syndrome includes minimizing environmental stimuli, promoting adequate rest and sleep and providing enough caloric ingestion to establish weight gain. Breastfeeding or feeding with human milk should be encouraged.

\section{CONCLUSION}

The use of opioids for acute postoperative pain is well established for minor, medium and major surgeries. Recommendations for the use of these drugs for neuropathic and musculoskeletal pain are restricted to second line of treatment and require further discussions. Most clinical trials have not contemplated multiple etiologies of such syndromes and it is not possible to anticipate in which patient or disease the opioid will be more effective and for how long, since in most studies the observation period was not long.

Few studies have investigated the interaction of opioids and physiological changes typical of gestation and the short and long term repercussions of the use of such agents to treat acute and chronic pain. Ongoing education on the subject is necessary, encouraging clinical research and the development of evidence-based recommendations.

\section{GROUP OF SPECIALISTS:}

Alexandre Annes Henriques

Anderson Arantes Silvestrini

Ângela Maria Sousa

Ariel de Freitas Q. Américo

Cláudio Fernandes Corrêa

Daniel Ciampi Andrade

Eduardo Grossmann

Erich Talamoni Fonoff

Gualter Lisboa Ramalho

Guilherme A. M. de Barros

Grace Haber

Inês T. V. e Melo

Irimar De Paula Posso

Janaina Vall

João Marcos Rizzo

João Valverde Filho

José Oswaldo de Oliveira Júnior

Judymara Lauzi Gozzani

Karine A. S. Leão Ferreira

Lia Rachel C. do Amaral Pelloso 

pain, neuropathic pain, gestation and lactation)

Lin Tchia Yeng
Manoel Jacobsen Teixeira
Mario Luiz Giublin
Maria Teresa R. Jalbut Jacob
Miriam Seligman Menezes
Mirlane Guimarães Cardoso
Newton Monteiro de Barros
Onofre Alves Neto
Patrick Raymond Stump
Rioko Kimiko Sakata
Roberto T. de Castro Bettega
Rogério Teixeira
Sandra Caires Serrano
Sílvia Maria de Macedo Barbosa
Telma M. Zakka
Theodora Karnakis
Toshio Chiba
Waleska Sampaio
William Gêmio Teixeira
William Jacobsen Teixeira

\section{ACKNOWLEDGMENTS}

This recommendation was developed by the Brazilian Society for the Study of Pain with support of Janssen do Brazil.

\section{REFERENCES}

1. Macintyre PE, Walker SM. The scientific evidence for acute pain treatment. Curr Opin Anaesthesiol. 2010;23(5):623-8.

2. Walder B, Schafer M, Henzi I, Tramèr MR. Efficacy and safety of patient-controlled opioid analgesia for acute postoperative pain. A quantitative systematic review. Acta Anaesthesiol Scand. 2001;45(7):795-804.

3. Duarte LT, Fernandes Mdo C, Costa VV, Saraiva RA. [The incidence of postoperative respiratory depression in patients undergoing intravenous or epidural analgesia with opioids]. Rev Bras Anestesiol. 2009;59(4):409-20. Portuguese.

4. Fredheim OM, Borchgrevink PC, Kvarstein G. [Post-operative pain management in hospitals. Tidsskr Nor Laegeforen. 2011;131(18):1772-6. Norwegian.

5. Hudcova J, McNicol E, Quah C, Lau J, Carr DB. Patient controlled opioid analgesia versus conventional opioid analgesia for postoperative pain. Cochrane Database Syst Rev. 2006;18(4):CD003348.

6. Werawatganon T, Charuluxanun S. Patient controlled intravenous opioid analgesia versus continuous epidural analgesia for pain after intra-abdominal surgery. Cochrane Database Syst Rev. 2005;25(1):CD004088.

7. Smith AB, Ravikumar TS, Kamin M, Jordan D, Xiang J, Rosenthal N. CAPSS-115 Study Group. Combination tramadol plus acetaminophen for postsurgical pain. Am J Surg. 2004;187(4):521-7.

8. Rothwell MP, Pearson D, Hunter JD, Mitchell PA, Graham-Woollard T, Goodwin $\mathrm{L}$, et al. Oral oxycodone offers equivalent analgesia to intravenous patient-controlled analgesia after total hip replacement: a randomized, single-centre, non-blinded, non-inferiority study. Br J Anaesth. 2011;106(6):865-72.

9. Ginosar Y, Riley ET, Angst MS. The site of action of epidural fentanyl in humans: the difference between infusion and bolus administration. Anesth Analg. 2003;97(5):1428-38

10. Gupta A, Bodin L, Holmström B, Berggren L. A systematic review of the peripheral analgesic effects of intraarticular morphine. Anesth Analg. 2001;93(3):761-70.

11. Capdevila X, Barthelet Y, Biboulet P, Ryckwaert Y, Rubenovitch J, d'Athis F. Effects of perioperative analgesic technique on the surgical outcome and duration of rehabilitation after major knee surgery. Anesthesiology. 1999;91(1):8-15.

12. Bruera E, Fainsinger R, Spachynski K, Babul N, Harsanyi Z, Darke AC. Steady-state pharmacokinetic evaluation of a novel, controlled-release morphine suppository and subcutaneous morphine in cancer pain. J Clin Pharmacol. 1995;35(7):666-72.

13. Breda M, Bianchi M, Ripamonti C, Zecca E, Ventafridda V, Panerai AE. Plasma morphine and morphine-6-glucuronide patterns in cancer patients after oral, subcutaneous, sublabial and rectal short-term administration. Int J Clin Pharmacol Res. 1991;11(2):93-7.

14. Derry S, Moore RA, McQuay HJ. Single dose oral codeine, as a single agent, for acute postoperative pain in adults. Cochrane Database Syst Rev. 2010;14(4):CD008099.
15. Picard PR, Tramèr MR, McQuay HJ, Moore RA. Analgesic efficacy of peripheral opioids (all except intra-articular): a qualitative systematic review of randomized controlled trials. Pain. 1997;72(3):309-18.

16. Khan MI, Walsh D, Brito-Dellan N. Opioid and adjuvant analgesics: compared and contrasted. Am J Hosp Palliat Care. 2011;28(5):378-83.

17. Lu JK, Schafer PG, Gardner TL, Pace NL, Zhang J, Niu S, et al. The dose-response pharmacology of intrathecal sufentanil in female volunteers. Anesth Analg. 1997;85(2):372-9.

18. Bucklin BA, Chesnut DH, Hawkins JL. Intrathecal opioids versus epidural local anesthetics for labor analgesia: a metaanalysis. Reg Anesth Pain Med. 2002;27(1):23-30.

19. American Society of Anesthesiologists Task Force on Neuraxial Opioids, Horlocker TT, Burton AW, Connis RT, Hughes SC, Nickinovich DG, Palmer CM, et al. Practice guidelines for the prevention, detection, and management of respiratory depression associated with neuraxial opioid administration. Anesthesiology. 2009;110(2):218-30.

20. Bjordal JM, Klovning A, Ljunggren AE, Slørdal L. Short-term efficacy of pharmacotherapeutic interventions in osteoarthritic knee pain. A meta-analysis of randomised placebo-controlled trials. Eur J Pain. 2007;11(2):125-38

21. Gana TJ, Pascual ML, Fleming RR, Schein JR, Janagap CC, Xiang J, et al. Extended-release tramadol in the treatment of osteoarthritis: a multicenter, randomized, double-blind, placebo-controlled clinical trial. Curr Med Res Opin. 2006;22(7):1391-401.

22. Cepeda MS, Camargo F, Zea C, Valencia L. Tramadol for osteoarthritis: a systematic review and metaanalysis. J Rheumatol. 2007;34(3):543-55.

23. Peloso PM, Bellamy N, Bensen W, Thomson GT, Harsanyi Z, Babul N, et al. Double blind randomized placebo control trial of controlled release codeine in the treatment of osteoarthritis of the hip or knee. J Rheumatol. 2000;27(3):764-71.

24. Taylor R Jr, Raffa RB, Pergolizzi JV Jr. Controlled release formulation of oxycodone in patients with moderate to severe chronic osteoarthritis: a critical review of the literature. J Pain Res. 2012;5:77-87.

25. Caldwell JR, Rapoport RJ, Davis JC, Offenberg HL, Marker HW, Roth SH, et al Efficacy and safety of a once-daily morphine formulation in chronic, moderate-to-severe osteoarthritis pain: results from a randomized, placebo-controlled, double-blind trial and an open-label extension trial. J Pain Symptom Manage. 2002;23(4):278-91.

26. White AP, Arnold PM, Norvell DC, Ecker E, Fehlings MG. Pharmacologic Management of Chronic Low Back Pain. Synthesis of the Evidence. Spine. 2011;36(21S):S131-43.

27. Chaparro LE, Furlan AD, Deshpande A, Mailis-Gagnon A, Atlas S, Turk DC. Opioids compared with placebo or other treatments for chronic low back pain: an update of the Cochrane review. Spine. 2014;39(7):556-63.

28. Bennett RM, Kamin M, Karim R, Rosenthal N. Tramadol and acetaminophen combination tablets in the treatment of fibromyalgia pain: a double-blind, randomized, placebo-controlled study. Am J Med. 2003;114(7):537-45.

29. Painter JT, Crofford LJ. Chronic opioid use in fibromyalgia syndrome: a clinical review. J Clin Rheumatol. 2013;19(2):72-7

30. Eisenberg E, McNicol ED, Carr DB. Efficacy and safety of opioid agonists in the treatment of neuropathic pain of nonmalignant origin. Systematic review and meta-analysis of randomized controlled trials. JAMA. 2005;293(1):22-9.

31. Eisenberg E, McNicol ED, Carr DB. Efficacy of mu-opioid agonists in the treatment of evoked neuropathic pain: Systematic review of randomized controlled trials. Eur J Pain. 2006;10(8):667-76

32. Finnerup NB, Sindrup SH, Jensen TS. The evidence for pharmacological treatment of neuropathic pain. Pain. 2010;150(3):573-81.

33. Canadian Guideline for Safe and Effective Use of Opioids for Chronic Non-Cancer Pain. Canada: National Opioid Use Guideline Group (NOUGG); 2010. Available from: http://nationalpaincentre.mcmaster.ca/opioid/

34. Finnerup NB, Otto M, McQuay HJ, Jensen TS, Sindrup SH. Algorithm for neuropathic pain treatment: an evidence based proposal. Pain. 2005;118(3):289-305.

35. Dworkin RH, O’Connor AB, Audette J, Baron R, Gourlay GK, Haanpää ML, et al. Recommendations for the pharmacological management of neuropathic pain: an overview and literature update. Mayo Clin Proc. 2010;85(3):S3-14.

36. Furlan AD, Sandoval JA, Mailis-Gagnon A, Tunks E. Opioids for chronic pain: meta-analysis of effectiveness and side effects, CMAJ. 2006;174(11):1589-94.

37. EUA. Departamet of Health and Humans Service. U.S. Food and Drug Administration (FDA) - center for Drug Evaluation and Research. Disponivel em URL:http:// www.fda.gov/cder/index.html.

38. Yankowitz J, Niebyl JR. Drug therapy in pregnancy. 3th ed, Philadelphia: Lippincott, Williams\&Wilkins; 2001.

39. Hudak ML, Tan RC. Committee on drugs: Committee on fetus and newborn. American Academy of Pediatrics. Neonatal drug withdrawal. Pediatrics. 2012;129(2):e540-60.

40. EUA. Department of Health and Humans Service. U.S. Food and Drug Administration (FDA) - center for Drug Evaluation and Research. Disponível em URL:http:// www.fda.gov/cder/index.html.

41. Ellwood DA, Sutherland P, Kent C, O'Connor M. Maternal narcotic addiction: pregnancy outcome in patients managed by a specialized drug-dependency antenatal clinic. Aust N Z J Obstet Gynaecol. 1987;27(2):92-8.

42. Dryden C, Young D, Hepburn M, Mactier H. Maternal methadone use in pregnancy: factors associated with the development of neonatal abstinence syndrome and implications for healthcare resources. BJOG. 2009;116(5):665-71.

43. American Academy of Pediatrics Committee on Drugs: The transfer of drugs and other chemicals into human milk. Pediatrics. 1994;93(1):137-50. 
44. Behravan J, Piquette-Miller M. Drug transport across the placenta, role of the ABC drug efflux transporters. Expert Opin Drug Metab Toxicol. 2007;3(6):819-30.

45. de Barros Duarte L, Moisés EC, Carvalho Cavalli R, Lanchote VL, Duarte G, da Cunha SP. Distribution of fentanyl in the placental intervillous space and in the different maternal and fetal compartments in term pregnant women. Eur J Clin Pharmacol. 2009;65(8):803-8.

46. Eisenach JC, Grice SC, Dewan DM. Patient-controlled analgesia following cesarean section: a comparison with epidural and intramuscular narcotics. Anesthesiology. 1988;68(3):444-8.

47. American Academy of Pediatrics Committee on Drugs. Use of psychoactive medication during pregnancy and possible affects on the fetus and newborn. Pediatrics. 2000;105(4):880-7.

48. Federação Brasileira das Sociedades de Ginecologia e Obstetrícia. Manual de Orienta- ção. Drogas na Gravidez. São Paulo: Ponto Editora; 2003. 9-12p.

49. Andrade SE, Gurwitz JH, Davis RL, Chan KA, Finkelstein JA, Fortman K, et al Prescription drug use in pregnancy. Am J Obstet Gynecol. 2004;191(2):398-407.

50. Canadian Guideline for Safe and Effective Use of Opioids for Chronic Non-Cancer Pain. In: National Opioid Use Guideline Group. 2010, part B, 53-4.

51. Malek A, Obrist C, Wenzinger S, von Mandach U. The impact of cocaine and heroin on the placental transfer of methadone. Reprod Biol Endocrinol. 2009;7:61.

52. van Baar AL, Soepatmi S, Gunning WB, Akkerhuis GW. Development after prenatal exposure to cocaine, heroin and methadone. Acta Paediatr Suppl. 1994;404:40-6.

53. Federaçấo Brasileira das Sociedades de Ginecologia e Obstetrícia. Manual de Aleitamento Materno. São Paulo; 2010. 77-86p.

54. Fortinguerra F, Clavenna A, Bonati M. Psychotropic drug use during breastfeeding: a review of the evidence. Pediatrics. 2009;124(4):e547-56. 